\title{
OBJETOS DA VIOLÊNCIA: AS FORMAS DO PATHOS NAS COMPOSIÇÕES DE YAEL MARTINEZ, Glenna Gordon e Eugênio Grosso
}

\author{
Eliza Bachega Casadei \& Mariana Duccini
}

\begin{abstract}
Resumo
O objetivo do presente artigo é estudar a obra artística dos fotógrafos Yael Martínez, Glenna Gordon e Eugenio Grosso. Em comum, suas fotografias tematizam a violência a partir da representação de objetos de consumo que evocam a relação de extensão entre o sujeito e seus pertences pessoais justamente como forma de problematizar a iconologia mesma desses objetos, que são convertidos para outras significações. A partir do estudo das estratégias de composição desses fotógrafos, iremos analisar as formas de pathos evocadas por eles através da montagem de imagens anacrônicas e dialéticas, em imagens que articulam o referencial ao esvaziamento da iconografia como ato político e memorialístico.
\end{abstract}

\section{Palavras-chave}

Anacronismo; arte; dialética; formas do pathos, fotografia

\begin{abstract}
This article aims to investigate the photographers' Yael Martínez, Glenna Gordon and Eugenio Grosso artistic works. Their photographs highlight the violence in representation of consumer goods which evoke the extended relations between the subjects and their personal belongings. This is a way to discuss the iconological status in such objects which are then converted in other significations patterns. The study of these artists' composition strategies allows us to analyze the pathos-forms achieved by the anachronistic and dialectical montage which links the referential aspects and the decrease of iconological status in these images.
\end{abstract}

\section{Keywords}

Anachronism; arts; dialectics; pathos-forms; photography

\section{ENTRE A AUSÊNCIA DOS CORPOS, A PRESENÇA DO OBJETO E O CHAMADO PARA A POLÍ́TICA: A REVOGAÇÃO DA ICONOLOGIA}

Dentre os conceitos basilares que fundamentam a epistemologia dos estudos contemporâneos dos objetos de consumo e sua relação com a comunicação, está o pressuposto de que eles não são meros aportes utilitários para a vida diária, mas sim sistemas de códigos e significações que funcionam imaginariamente como extensões do sujeito e de suas afiliações identitárias. É nesse sentido que Douglas e Isherwood afirmam que "dizer de um objeto que ele está apto para o consumo é o mesmo que dizer que o objeto 
está apto a circular como marcador de conjuntos particulares de papéis sociais", de forma que "os bens em sua reunião apresentam um conjunto de significados mais ou menos coerentes, mais ou menos intencionais. Esses são lidos por aqueles que conhecem o código e os esquadrinham à cata de informação" (Douglas \& Isherwood, 2004, p. 28). Também para Bourdieu (2007), os objetos funcionam como marcadores dos desvios diferenciais a partir de retraduções simbólicas inscritas no habitus dos grupos sociais e seus processos de distinção. Trata-se de abordagens que partem de uma perspectiva iconológica dos objetos diários, calcada nos simbolismos latentes nas representações visuais. Algumas obras artísticas, contudo, problematizam a questão da relação entre o objeto e o sujeito, de forma que o ponto de vista teórico alicerçado na mera iconologia dos objetos não consegue dar conta das estratégias e dos efeitos de sentido ali implicados. A partir desse pressuposto, o objetivo do presente artigo é estudar a obra de fotógrafos que tematizam os objetos de consumo e evocam, em seus trabalhos, a relação de extensão entre o sujeito e seus pertences pessoais como forma de problematizar a iconologia desses objetos, que são convertidos para outras significações ao entrarem nos circuitos da arte.

Como recorte temático, foram selecionadas obras de fotógrafos que, a partir de diferentes estratégias estéticas, fotografam objetos relacionados a situações de violência, a saber, Yael Martínez, Glenna Gordon e Eugenio Grosso. As imagens de Martínez, em "The House That Bleeds", contam, a partir do registro de objetos relacionados ao convívio familiar, as histórias das famílias do Estado mexicano de Guerrero cujos parentes foram vítimas de ações de violência; Gordon relata acontecimentos sobre as meninas nigerianas sequestradas pelo grupo militante islâmico Boko Haram, a partir do registro de objetos pertencentes a essas garotas em "Mass Abduction in Nigeria"2; por fim, Grosso registra em fotografias os documentos pertencentes a refugiados que foram encontrados no chão na fronteira da cidade macedônica de Gevgelija, em "Papers: Discarded Along Europe's Refugee Trails"3.

Em comum, os efeitos de pathos na obra dos três fotógrafos remetem à violência descorporificada e materializada em objetos fotografados que efetuam a marcação do eu destituída do sujeito, aproveitando-se dos processos de alienação do sujeito no objeto. Tais efeitos têm por correlata a assunção da imagem não como uma representação ilustrativa dos fatos de que são, em certa medida, a materialização ou o testemunho, mas como um meio de afetar o espectador, vinculando-o à dimensão do sofrimento que torna sensíveis (em termos dos aspectos fenomenológicos dessas imagens) determinadas linhas de força da história contemporânea.

A anomia representada pela ausência dos corpos, nessas obras, faz o chamado para a revogação do anonimato das vítimas nos objetos, na tentativa de estabelecer

\footnotetext{
' Retirado de https://www.lensculture.com/articles/yael-martinez-the-house-that-bleeds-mexico-s-disappeared\#slide-1

${ }^{2}$ Retirado de http://www.worldpressphoto.org/collection/photo/2015/general-news/glenna-gordon

${ }^{3}$ Retirado de https://www.lensculture.com/articles/eugenio-grosso-papers-discarded-along-europe-s-refugee-trails\#slide-1
} 
novas formas de visibilidade e pensabilidade 4 a partir da mostração de outras configurações de divisão e partilha do espaço social. Em consonância com a modulação contemporânea das novas formas de realismo, em que a verosimilhança de certos discursos referenciais (entre eles, o fotográfico) se assenta não tanto na referencialidade, mas especialmente nos índices que atestam uma presença subjetiva como lastro daquilo que se dá a ver (seja no âmbito da instância enunciativa, seja na dimensão do que se apreende em termos do enunciado), esses trabalhos são rentabilizados por uma dinâmica paradoxal: servem-se do caráter reificado dos objetos enquadrados ao mesmo tempo em que apontam para o contexto que os ultrapassa, em que o indício de uma singularidade se torna determinante, imiscuindo o aspeto referencial ("o que é isso?") ao subjetivo ("de quem é/foi isso?").

Trata-se de imagens que evocam a sensibilização para a experiência estética que se dá a partir de um consumo específico das imagens de violência no circuito da receção artística com o intuito de restituir uma suposta identidade a corpos sem nome. A questão que se impõe, contudo, é: em que termos se daria essa experiência? Partimos do pressuposto de que, a partir de diferentes estratégias composicionais, as obras desses fotógrafos não fazem uma convocação para a ação, no sentido de uma intervenção direta na realidade, visto que:

enquanto a política propriamente dita consiste na produção de sujeitos que dão voz aos anônimos, a política própria à arte (...) consiste na elaboração do mundo sensível do anônimo, dos modos do isso e do eu, do qual emergem os mundos próprios do nós político. Mas, à medida que passa pela ruptura estética, esse efeito não se presta a nenhum cálculo determinável. (Rancière, 2012b, p. 65)

A dinâmica dessas obras responderia por uma revogação do estatuto iconológico do objeto a partir da montagem de imagens dialéticas e anacrônicas que se utilizam da montagem temporal como gatilho de seus principais efeitos de sentido. Produções inseridas em um universo simbólico, elas são tributárias das formas contemporâneas de inteligibilidade dos fenômenos de violência - e dos próprios limites do que pode ser comunicado, a partir deles, como experiência coletiva. Isso porque, se a figurativização das vítimas por meio de seus fragmentos metonímicos aponta para configurações até então inauditas de um mundo sensível, ao mesmo tempo, a ligação inextrincável entre a violência e os sujeitos vitimados (como forma contemporânea de veridicção dos discursos sobre a própria violência) obscurece os parâmetros que apontam para uma lógica social que explicaria tanto as formas de perpetração da violência quanto a emergência do lugar de vítima como uma categoria socialmente construída.

\footnotetext{
4 Entendemos as formas de visibilidade e de pensabilidade como o engendramento de regimes específicos próprios a determinada conjuntura histórica, que articulam a relação entre a circulação de imagens e os modos de interpretação e valoração delas pelo corpo social.
} 


\section{AS FORMAS DO PATHOS, O ANACRONISMO COMO ESTRATÉGIA COMPOSICIONAL E A IMAGEM DIALÉTICA}

A falha das abordagens que enxergam os objetos visuais como sistemas de códigos coerentes, para Didi-Huberman (2013a, p. 310), está em supor "a transparência mimética do signo icônico", "como se todo quadro funcionasse como um texto, e como se todo texto fosse legível e integralmente decifrável". Ao entendimento que tenta conciliar as representações visuais e seus valores simbólicos a partir de uma perspetiva iconológica, Didi-Huberman irá contrapor um ponto de vista em que a primazia do significado dá lugar à dinâmica da dialética, a partir da recusa de uma leitura da imagem (e dos objetos nela representados) como uma simples imageria estereotipada. $O$ autor reivindica a necessidade de uma semiologia não-iconológica para o entendimento da imagem, ou seja, "uma semiologia que não fosse nem positivista (a representação como espelho das coisas), nem mesmo estruturalista (a representação como sistema de signos)" (Didi-Huberman, 2015, p. 18).

Na perspectiva de Didi-Huberman (2015, p. 15), toda a imagem - inclusive as estáticas - supõe uma duração, de forma que "sempre, diante da imagem, estamos diante do tempo". E isso no sentido de que há diferenciais de tempos operando em cada imagem, de forma que ela se constitui pela montagem de temporalidades heterogêneas que conformam anacronismos. Nesse sentido, toda imagem é constituída por uma montagem das diferenças temporais, a partir da perspetiva de que um artista, ao articular uma representação, não remete apenas a um sistema de signos de seu próprio tempo presente, mas sim, opera uma montagem de reminiscências de sistemas de significações passados e anacrônicos, somados, ainda, a outros sistemas de significações futuros que irão compor o contexto de recepção dessa obra em diferentes eixos temporais (com os anacronismos da própria interpretação). Tal questão está relacionada à ideia de que "conectar-se ao mundo de duas dimensões é correlacionar o que se está a ver com o que já se viu, com a pose que já se fez, com aquele instante comum a sua e a família do outro", de forma a levar "o observador a receber, em mente, outras imagens, daquilo que conserva na memória, 'sem chegar a ver realmente o retrato que lhe é apresentado' (Leite, 2001, p. 75)" (Pinheiro \& Cabral, 2010, p. 36).

Tal perspetiva implica reconhecer que os significados dos objetos não são estáticos e mudam ao longo do tempo. Implica, ainda, assumir que a imagem é um objeto impuro e complexo, de forma que os diferentes estratos temporais dos sistemas de significação se acumulam e se entrelaçam nas composições imagéticas. Implica, por fim, o reconhecimento da necessidade de uma "fenomenologia atenta principalmente aos processos, individuais e coletivos, da memória", visto que não há significação possível para a imagem "senão na montagem, no jogo rítmico, na contradança das cronologias e dos anacronismos" (Didi-Huberman, 2015, p. 42).

O anacronismo, portanto, não é uma impropriedade cronológica do discurso (como pretende a historiografia positivista), mas a irrupção de um regime de pensabilidade (ou de construção de verdades) em outro. O anacronismo, nesse aspecto, é a própria abertura para a construção de imagens dialéticas, na medida em que aproxima 
fenômenos heterogêneos no tempo e no espaço, expõe suas semelhanças e contiguidades, provocando uma abertura na própria imagem.

A imagem assim entendida - como uma dialética da montagem de camadas de significações de tempos sobreviventes - está submetida a um regime duplo: "o pathos com a fórmula" (Didi-Huberman, 2013b, p. 173). A expressão "formas do pathos na imagem" (pathosformel), portanto, remete à ideia de um "traço significante, um traçado em ato das imagens (...), algo pelo qual ou por onde a imagem pulsa, move-se, debate-se na polaridade das coisas". Trata-se da união de uma carga afetiva com uma fórmula iconográfica que se expressa na concorrência de tempos heterogêneos em uma mesma imagem. Para que o senso de historicidade possa ser constituído, portanto, faz-se necessária uma dinâmica própria às imagens, já que "não existe uma história por detrás das imagens, mas imagens que fazem história" (Mauad, 2014, p. 109). Se os tempos heterogêneos se condensam - e sobrevivem - nas superfícies imagéticas, isso se dá porque o passado ou mesmo o futuro não podem ser apreensíveis senão como imagens: ora daquilo que já não existe, ora daquilo que ainda aguarda por novas formas de percepção para que sua condição de enigma possa dar lugar a determinados vetores de inteligibilidade, concernentes a práticas sociais historicamente situadas.

É aqui que a perspetiva do referente cede lugar à imagem dialética. Na reflexão de Didi-Huberman (2010, p. 171), a imagem dialética é aquela que "critica nossas maneiras de vê-la (...), nos obriga a escrever esse olhar, não para 'transcrevê-lo', mas para constituí-lo". E isso significa que se trata de uma imagem que figura para além dela própria ou, em outros termos, que obriga a uma síntese entre significações diversas para além daquilo que está exposto no registro do visível. A possibilidade de "redenção da memória" inscrita em uma fotografia "constitui então um projeto essencial no presente não só porque tem o poder de reconsiderar e de reescrever a história oficial, mas também porque possui a capacidade de confirmar identidades previamente marginalizadas" (Stewart, 2016, p. 243). Ultrapassando o âmbito da mera visibilidade, a imagem dialética opera, assim, em termos de uma legibilidade: a capacidade de conjugar o passado e o presente de modo a instilar, na aparente passividade iconográfica, a descontinuidade e o choque que suscitariam novos modos de percepção sobre o continuum da história. Assim, não há "imagem dialética sem um trabalho crítico da memória, confrontada a tudo o que resta como ao indício de tudo o que foi perdido" (Didi-Huberman, 2010, p. 174).

A especificidade das fotografias de Martínez, Gordon e Grosso está no fato de que elas não apenas se apoiam na anacronicidade constituinte da imagem fotográfica, mas também constroem o lugar da falta na própria composição imagética a partir da ênfase na ausência do corpo e na insistência do eu destituído do sujeito (marcado pela presença do objeto como marca de subjetivação). Como, diante disso, interpretar os objetos representados na fotografia desses artistas? Diante do exposto, não é mais possível interpretá-los como meros sistemas de signos coerentes e estáticos que marcam a continuidade entre a ausência do eu e a presença do objeto. E isso no sentido de que "em cada objeto histórico todos os tempos se encontram, entram em colisão ou, ainda, se fundem plasticamente uns nos outros, se bifurcam ou se confundem uns nos outros" (Didi-Huberman, 2015, p. 46). 
Mais do que meros sistemas de significação que marcam a continuidade identitária entre sujeito e objeto, cada pertence pessoal representado nessas fotografias se constitui como uma forma de pathos, reivindicando muito mais um processo de caráter dialético do que uma relação de pertinência entre o objeto e o indivíduo pautada pelos processos de construção identitária. Somam-se a isso, ainda, os efeitos de indicialidade engendrados nessas composições, respaldado por uma espécie de princípio geral que aproxima a fotografia de uma "transparência estritamente seletiva", em que, entretanto, "apesar da presunção de veracidade que confere autoridade, interesse e sedução a todas as fotos, a obra que os fotógrafos produzem não constitui uma exceção genérica ao comércio usualmente nebuloso entre arte e verdade" (Sontag, 2004, p. 16). Nesse sentido, é necessário analisar, nas obras, seus efeitos de estilo e seus efeitos de verdade como forma de entender os efeitos de pathos nelas articulados.

\section{EFEITOS DE ESTILO, EFEITOS DE VERDADE, EFEITOS DE PATHOS}

As fotografias mais violentas nem sempre são aquelas que remetem ao choque gráfico da dor dos corpos dilacerados. A estratégia das obras de Martínez, Gordon e Grosso está justamente em retratar a violência de forma indireta para melhor explicitá-la, remetendo à banalidade dos objetos cotidianos para conotar aquilo que falta: a presença aberrante do indivíduo ausente.

As fotografias de Martínez são motivadas por uma tragédia familiar: em 2013, três de seus cunhados desapareceram em situações de violência em Guerrero, um dos estados mexicanos mais afetados pelo crime organizado5. Em "The House that Bleeds", o fotógrafo documenta o processo de luto de sua família e da família de outros desaparecidos. Nas imagens, é possível observar a relação dos parentes (que são sempre retratados a partir de partes de seus corpos, nunca de corpos inteiros e, muitas vezes, sem mostrar o rosto) com os objetos e espaços frequentados pelos desaparecidos.

A figurativização do trauma da perda é adensada precisamente pelos rastros da violência que invadem o espaço privado do lar. Se, contemporaneamente, a performativização da intimidade tornou-se um dos moduladores principais da afirmação subjetiva (a capacidade de automostração como condição existencial), com ênfase na laboriosa construção dos corpos segundo os protocolos da perfeição plástica e da incorruptibilidade, Martínez é tributário de uma tendência já presente em determinadas produções artísticas dos anos 1960-70, em que a contrapartida do humanismo racionalista elege como matéria estética os corpos fragmentados, não raramente expostos em sua pura materialidade orgânica (Sibilia, 2013). Entretanto, a disposição da incompletude corpórea como analogia do próprio aniquilamento psíquico dos sujeitos fotografados, em "The House that Bleeds", reveste a estratégia composicional de um efeito de ambiguidade: a dissolução física/psíquica dos personagens retratados é "encapsulada" pela ambientação em certa medida protetora dos lares. Desse modo, no mesmo movimento

5 Trata-se do mesmo Estado onde se deu o conhecido episódio do desaparecimento dos 43 estudantes da Escola Normal Rural Raúl Isidro Burgos, em setembro de 2014, em virtude de uma ação da polícia mexicana. 
em que a presença da violência se materializa como uma evidência cotidiana da vida dos indivíduos, o enclausuramento próprio aos espaços retratados tende a limitar esse panorama ao lugar dos sujeitos, obliterando aspetos de uma dinâmica político-social em que a tortura e o assassinato generalizaram-se, seja nas ações do crime organizado seja na conduta repressiva do Estado, como a resposta-padrão às situações de conflito.

Os resquícios da violência nos corpos daqueles que "restaram", diretamente afetados pela dissolução dos laços familiares, engendra a produção de fotografias em que o simbolismo se rentabiliza pelo sentido de incomunicabilidade correlato às ações brutalizantes. Como componente dessa construção estilística, muitas das imagens servem-se de uma espécie de "teatralização" da morte nos corpos animados (ainda que estáticos), como aquela em que uma criança é quase totalmente envolta em uma toalha rota, à guisa de mortalha ${ }^{6}$. Por meio de informações indexadoras, sabemos que a personagem é Itzel Martínez, filha do fotógrafo, após sair do banho. São composições em que o efeito de choque só pode ser relativizado por meio de dados contextuais, quando, então, torna-se sensível a disposição da instância enunciadora em propor um nível metafórico para a leitura das fotografias. Ao mesmo tempo em que se imiscui nos espaços de intimidade, a câmera assume uma estratégia que não deixa de lograr o espectador: as reminiscências da morte são engendradas de maneira tácita, indireta. É assim que as imagens expressam uma relação posicional entre uma "consciência" que produz a obra (a condição autoral) e o objeto retratado, que condensa, em termos de simbolismo, significados heterogêneos. A morbidez que permeia vidas singulares e, ao mesmo tempo, a particularidade dessas mesmas vidas, que resistem à morte, tornam-se, assim, os paradoxos expressivos da série fotográfica de Martínez.

Se a articulação metafórica anteriormente explicitada na análise de uma das obras opera conforme um procedimento de identificação por similaridade - a condensação de significados que aponta para uma espécie de substituição, ou seja, um desvio de sentido em que um domínio da experiência (a vitimização direta, imediata, em virtude de ações violentas) é sobreposto por outro (as repercussões dessa violência em um grupo de indivíduos extensivo às vítimas) -, as estratégias composicionais do fotógrafo não prescindem, igualmente, de uma articulação metonímica. Nela, o procedimento da contiguidade propõe uma evocação de sentidos não exatamente pela substituição entre domínios diferentes da experiência, mas por um "deslizamento" de referências, ou seja, pela ativação de correspondências entre fragmentos expressivos de uma totalidade: partes que indiciam o todo. Não se trata, no âmbito desta análise, de dicotomizar as obras da série "The House that Bleeds" em termos de uma impertinente classificação que as dispusesse conforme a orientação metafórica ou metonímica de cada uma das fotografias. Essas duas estratégias conjugam-se como princípios de inteligibilidade na estruturação dos enunciados fotográficos - e não apenas como recursos formais detetáveis na superfície imagética. É, com efeito, pela assunção de elementos (referenciais ou figurados) que se relacionam a uma totalidade que se instila o próprio desvio de sentido próprio à dinâmica da arte: a emergência de determinado domínio da experiência social em outro.

\footnotetext{
${ }^{6}$ Retirado de https://www.lensculture.com/articles/yael-martinez-the-house-that-bleeds-mexico-s-disappeared\#slide-1
} 
As pétalas de flores que restaram do funeral de Javier Granda7, uma das vítimas aludidas na série de Martínez, são um exemplo dessa conexão simbólica. Com a figurativização de fragmentos, resquícios daquilo que já não existe, as fotografias apontam, ao mesmo tempo, para uma completude perdida e para uma ausência que segue produtiva, determinando novas posições subjetivas em relação aos que foram afetados pela perda, assim como desses sujeitos com o cotidiano contingente. As pétalas espalham-se pelo piso, delineando um sentido de incontinência: se são insuficientes para repor o que falta, são também bastantes para materializar, metaforicamente, os efeitos dessa perda.

Já Gordon, em "Mass Abduction in Nigeria"8, opta por estratégias de composição relativamente mais distanciadas, pelo fato de que a presença da primeira pessoa enunciativa, em contraste com o trabalho de Martínez, é sensivelmente menos explícita na série. Suas fotografias, ganhadoras do segundo lugar na categoria general news do World Press Photo de 2015, retratam os objetos pertencentes às meninas sequestradas pelo grupo islâmico Boko Haram no ano anterior. O grupo se opõe à educação secular para as meninas e suas ações incluem o ataque a escolas, o sequestro de alunos e a realização de recrutamentos forçados. Os uniformes escolares, brincos, cadernos e demais pertences das garotas são organizados na fotografia sob um fundo neutro, preto, sem identificação (mais uma vez, em contraste com algumas das fotografias de Martínez, que indexam, nos textos que as acompanham, informações relativas às vítimas ou a seus familiares).

A não identificação das estudantes sequestradas, entretanto, não trabalha em vista de uma desarticulação dos efeitos de pathos: eles, ao contrário, são adensados como estratégia enunciativa por meio dos objetos enquadrados. Mais do que vestígios testemunhais pertencentes às vítimas, esses elementos compõem um universo afetivo bastante particular. O desgaste visível nos uniformes, sandálias e materiais escolares, por exemplo, remete à dimensão da vida e da atividade juvenis, prematuramente destruídas pelas ações terroristas. Ainda que não se explicite a atribuição de um pertencimento específico, as fotografias circunscrevem todo um segmento social especialmente vulnerável à violência (o número de meninas sequestradas pelo grupo terrorista apenas na ação de 14 abril de 2014 chega a quase 300).

A ênfase em se retratar sobretudo os objetos próprios ao mundo escolar, adicionalmente, propulsiona uma crítica, nessa obra de Gordon, às perseguições sofridas pelo sistema educacional laico no país (em tradução livre a partir da língua hausa, a expressão "boko haram" significa: "a educação ocidental é proibida" ${ }^{9}$ ). Ao mesmo tempo, a referida disposição dos objetos sobre o fundo preto, para além do sentido de isolamento que engloba cada uma das peças, alude metaforicamente ao próprio desamparo das vítimas e ao alheamento do público (sobretudo do ocidental, a quem as fotografias preferencialmente se destinam) quanto a essa vulnerabilidade.

\footnotetext{
${ }_{7}^{7}$ Retirado de https://www.lensculture.com/articles/yael-martinez-the-house-that-bleeds-mexico-s-disappeared\#slide-1

${ }^{8}$ Retirado de http://www.worldpressphoto.org/collection/photo/2015/general-news/glenna-gordon

9 Ver a esse respeito http://www1.folha.uol.com.br/mundo/2014/05/1449621-saiba-mais-como-surgiu-o-boko-haram-na-nigeria.shtml
} 
Dessa forma, ao passo que "a representação clássica cria um espaço contínuo no qual são dispostos, como entidades descontínuas, objetos e personagens" (Didi-Huberman, 2015, p. 218), as imagens de Gordon operam justamente pela dissociação desse espaço, ao solicitarem ao espectador uma nova posição de sujeito, ao movimentar o seu olhar das formas (representadas pelos objetos) para os processos mais amplos que não estão propriamente no nível da conotação, mas sim, na constituição de um espaço-problema da rememoração. O presente de suas fotografias, nesse sentido, não está posto no sentido da presença (na medida em que faz, justamente, trabalhar a ausência na composição), mas sim, no sentido da apresentação, que ultrapassa a própria representação e coloca a memória como eixo central de uma experiência que é construída na obra, embora remeta a processos sociais mais amplos inscritos na memória do espectador. Tais aspetos estão postos tanto na ausência dos dados contextuais (que depende da experiência de um espectador que preencha os brancos de sentido) quanto na evocação a uma memória afetiva (que dramatiza os personagens ausentes a partir de objetos escolares presentes e remete a um repertório memorialístico que, a despeito das diferenças culturais, é também comum ao espectador da obra). Trata-se da constituição de um espaço-reminiscência que apela à própria experiência subjetiva do espectador na obra.

Por fim, em "Papers"10, Grosso fotografa os documentos descartados por refugiados na fronteira da cidade de Gevgelija, na fronteira da Macedônia com a Grécia. Segundo a descrição do próprio fotógrafo, "ao longo desse caminho, a cada dia, os documentos gregos temporários são jogados fora junto com listas de nomes, mapas e pedidos de asilo. Imediatamente após a saída do país (Grécia) que emitiu esses documentos, os refugiados retornam ao status de clandestinos. Suas identidades têm de ser confirmadas novamente em todos os países em que entram" ". A composição escolhida por Grosso também é bastante minimalista, composta pelo enquadramento do documento no chão onde foi encontrado (usualmente esses papéis trazem fotografias dos refugiados), sem identificações mais exatas do cenário em que se desenrola a narrativa.

Com a premissa de que um documento, sobretudo em circunstâncias tangentes à questão dos refugiados, é a principal marca identitária que franqueia ou impede o acesso dos sujeitos a melhores condições de vida, o trabalho de Grosso tematiza o aspecto das “identidades descartáveis". Ali, a metáfora da violência incide diretamente sobre os índices retratados: dispensados, rasgados, pisoteados, esses objetos evocam um processo sócio-histórico que vai conformando subjetividades precarizadas, já que apartadas de um pertencimento comunitário assim legitimado pela ordem do capitalismo tardio, em que já “não são fornecidos 'lugares' para a 'reacomodação', e os lugares que podem ser postulados e perseguidos mostram-se frágeis e frequentemente desaparecem antes que o trabalho de 'reacomodação' seja completado" (Bauman, 2001, p. 42).

Assim como na obra de Gordon, trata-se de uma composição fotográfica que remete aos aspectos iconológicos dos objetos pessoais justamente para desconstruí-los,

\footnotetext{
${ }^{10}$ Retirado dehttps://www.lensculture.com/articles/eugenio-grosso-papers-discarded-along-europe-s-refugee-trails\#slide-1 "Retirado de https://www.lensculture.com/articles/eugenio-grosso-papers-discarded-along-europe-s-refugee-trails\#slide-1
} 
ao remeter, em um aspeto que ultrapassa o visível, à projeção memorialística do espectador na obra, que é construída como composição e evocada como experiência.

Uma espécie de enunciação em segundo grau - as fotografias tomadas pelo artista sobre as fotografias destruídas pelos próprios refugiados, que além de não encontrarem mais serventia nos documentos ainda anteveem que eles podem se tornar um ônus - destina um sentido de permanência àquilo que se descartou. A série "Papers" joga assim com o efeito de duração próprio a toda fotografia, tendo por base, entretanto, enunciados cuja expressividade "primeira" se delineia pelo aspeto da transitoriedade compulsória. Ademais, o próprio caráter de violência inerente às fotos é revestido de uma acepção estética: a aniquilação materializada nos objetos enquadrados, para além da expressividade referencial, é mais um elemento a catalisar o choque percetivo que, em uma leitura dialética, demanda a constituição de um olhar que conjugue significados heterogêneos em um processo que exorbite a mera visibilidade rumo à inteligibilidade das imagens.

\section{ConclusÃo}

O efeito de pathos nas séries de imagens analisadas irá se articular, em um primeiro momento, a partir de um efeito de verdade. Sobre esse aspecto, Rancière (2012a) pontuará que as fotografias estruturam seus regimes de verdade a partir de uma dialética encarnada entre uma "performance da memória e da presença". Isso porque há uma dupla poética na fotografia que faz "de suas imagens, simultânea ou separadamente, duas coisas: os testemunhos legíveis de uma história escrita nos rostos ou nos objetos e puros blocos de visibilidade, impermeáveis a toda narrativização, a qualquer travessia de sentido" (Rancière, 2012a, p. 20). É assim que a imagem fotográfica se apresenta como "cifra de uma história escrita em formas visíveis e como realidade obtusa, obstruindo o sentido ou a história" (Rancière, 2012a, p. 20).

Nessa perspetiva, o autor reinterpreta a famosa formulação barthesiana do isso foi. Se "o nome do noema da fotografia será então 'isso foi'” (Barthes, 2012, p. 32), para Rancière tal asserção deve ser entendida a partir da junção de um efeito de verdade (o isso do referente) a um efeito de afeto (o foi da interpretação, que é negado ao observador). Toda a poética da fotografia se estrutura a partir do mistério, uma vez que ela "tornou-se uma arte pondo seus recursos técnicos a serviço dessa poética dupla, fazendo falar duas vezes o rosto dos anônimos: como testemunhas mudas de uma condição inscrita diretamente em seus traços, suas roupas, seus modos de vida" e "como detentores de um segredo que nunca iremos saber, um segredo roubado pela imagem mesma que traz esses rostos" (Rancière, 2012a, p. 23). Assim, "projetando a imediaticidade" do isso foi "sobre o processo de impressão maquínica, ela faz desaparecer todas as mediações entre o real da impressão maquínica e o real do afeto que tornam esse afeto experienciável, nominável, fraseável" (Rancière, 2012a, p. 24).

Ao mesmo tempo, o caráter dialético e anacrônico das imagens só pode ter pertinência se assumirmos, no ato de olhar, uma operação eminentemente subjetiva, ou seja, posta em marcha por sujeitos situados no tempo e no espaço: 
o ato de ver não é o ato de uma máquina de perceber o real enquanto composto de evidências tautológicas. $O$ ato de dar a ver não é o ato de dar evidências visíveis a pares de olhos que se apoderam unilateralmente do 'dom visual' para se satisfazer unilateralmente com ele. Dar a ver é sempre inquietar o ver, em seu ato, em seu sujeito. Ver é sempre uma operação de sujeito, portanto uma operação fendida, inquieta, agitada, aberta. (Didi-Huberman, 2010, p. 77)

Se a demanda de inteligibilidade (que ultrapassa a visibilidade) aos sujeitos que se postam diante de uma imagem pressupõe a inquietação do ver, o campo da arte parece, então, um dos locus mais favoráveis a essa experiência, precisamente por ser capaz de apresentar o "dado do mundo" conforme configurações até então inéditas de um espaço sensível comum. Entretanto, como produções de cultura, as obras fotográficas não têm como ser apreendidas alheiamente aos discursos circulantes que, em cada época histórica, conformam suas verdades situadas, particulares.

A se considerar a possibilidade de que os efeitos de pathos nas fotografias aqui contempladas tenham por contrapartida uma obliteração da capacidade crítica do espectador, esse panorama seria explicável por determinadas modulações dos discursos contemporâneos, em que a figura da vítima se torna o símbolo por excelência das manifestações tangentes à violência.

A vítima, nesse sentido, encerra "uma forma socialmente inteligível de expressar o sofrimento associado à violência, legitimando demandas e ações sociais de reparação e cuidado" (Sarti, 2011, pp. 56-57). Apesar da inquestionável necessidade de reconhecimento, nomeação e reparação das vítimas nos diversos contextos de perpetração da violência na contemporaneidade, a absolutização dessa categoria nos discursos sobre a violência tende, entretanto, à dispersão, no corpo social, de uma lógica em que a experiência do dissenso é reposta pela mera administração/tratamento do dano - e não pelo reconhecimento político dele, que deriva não em uma identificação com a vítima, mas em uma desidentificação com os perpetradores (Rancière, 1996). Em outras palavras, delimitar o problema da violência, como verdade contemporaneamente disseminada, à figura da vítima pode delinear uma forma de subjetivação pautada pela "reparação generalizada", sem que a violência seja encarada como um fenômeno social, diretamente relacionado a uma coletividade (e não como um problema circunscrito aos sujeitos).

Nesse âmbito, seria uma distorção - e uma ingenuidade - demandar das obras de Martínez, Gordon e Grosso, assim como de qualquer outro trabalho fotográfico per se, uma convocação à ação, tampouco julgá-los pelo suposto esvaziamento político que encerrariam. A leitura das imagens (a vinculação entre elas e um público espectador) é, como toda prática social, atravessada por parâmetros de veridicção que modulam nossas formas de relacionamento com o mundo. Entretanto, essas mesmas imagens, suficientes para inquietar um olhar já "pacificado" pelo estado das coisas, podem também propulsionar novas formas de recepção e de inteligibilidade, aspeto em que a leitura de uma obra de arte não pode ser desvinculada de seus processos comunicacionais. " 


\section{REFERÊNCIAS BIBLIOGRÁFICAS}

Barthes, R. (1984). A câmara clara. Rio de Janeiro: Nova Fronteira.

Bauman, Z. (2001). Modernidade líquida. Rio de Janeiro: Jorge Zahar Ed.

Bourdieu, P. (2007). A distinção: crítica social do julgamento. São Paulo: Edusp.

Didi-Huberman, G. (2010). O que vemos, o que nos olha. São Paulo: Editora 34.

Didi-Huberman, G. (2013a). Diante da imagem. São Paulo: Editora 34.

Didi-Huberman, G. (2013b). A imagem sobrevivente. Rio de Janeiro: Contraponto.

Didi-Huberman, G. (2015). Diante do tempo. Belo Horizonte: Editora UFMG.

Douglas, M. \& Isherwood, B. (2004). O mundo dos bens: para uma antropologia do consumo. Rio de Janeiro: Editora UFRJ.

Leite, M. M. (2001). Retratos de Família. São Paulo: Editora da Universidade de São Paulo.

Mauad, A. M. (2014). Como nascem as imagens. História: Questões Q Debates, 61, 105-132. Retirado de http:// revistas.ufpr.br/historia/article/view/39008/23769

Pinheiro, P. J. S. \& Cabral, E. M. (2010). Imagens da memória: a relação entre a fotografia e a formatação screen das lembranças visuais. Comunicação e Sociedade, 17, 31-38. Retirado de http://revistacomsoc.pt/ index.php/comsoc/article/view/1010

Rancière, J. (1996). O desentendimento: política e filosofia. São Paulo: Editora 34.

Rancière, J. (2012a). O destino das imagens. Rio de Janeiro: Contraponto.

Rancière, J. (2012b). O espectador emancipado. São Paulo: WWF Martins Fontes.

Sarti, C. A. (2011). Vítima como figura contemporânea. Caderno CRH, 24(61), 51-61. Retirado de https:// portalseer.ufba.br/index.php/crh/article/view/19193/12460

Sibilia, P. (2013). Os corpos visíveis na contemporaneidade: da purificação midiática à explicitação artística. In A. Brasil; E. Morettin \& M. Lissowski (Eds.), Visualidades Hoje (pp.119-136). Salvador: EDUFBA; Brasília: Compós.

Sontag, S. (2004). Sobre fotografia. São Paulo: Companhia das Letras.

Stewart, K. (2016). Entre a memória e o seu apagamento: O Grande Kilapy de Zézé Gamboa e o legado do colonialismo português. Comunicação e Sociedade, 29, 239-254. Retirado de http://revistacomsoc.pt/ index.php/comsoc/article/view/2418

\section{NOTAS BIOGRÁFICAS}

Eliza Bachega Casadei, Doutora em Ciências da Comunicação pela Escola de Comunicações e Artes da Universidade de São Paulo (ECA-USP), mestre em Ciências da Comunicação e graduada em Comunicação Social com Habilitação em Jornalismo, ambos pela ECA-USP. Professora titular do Programa de Pós-graduação em Comunicação e Práticas de Consumo da Escola Superior de Propaganda e Marketing (PPGCOM-ESPM). 
Email: elizacasadei@yahoo.com.br

ESPM - Campus Francisco Graciosa. Rua Dr. Álvaro Alvim, 123, Vila Mariana, 04018-010, São Paulo/SP, Brasil

Mariana Duccini, Doutora em Ciências da Comunicação pela Escola de Comunicações e Artes da Universidade de São Paulo (ECA-USP), mestre em Ciências da Comunicação pela mesma instituição e graduada em Comunicação Social com Habilitação em Jornalismo pela Universidade Estadual Paulista Júlio de Mesquita Filho (UNESP). Pós-doutoranda no Programa de Multimeios da Universidade Estadual de Campinas (UNICAMP - PNPD/Capes).

E-mail:marianaduccini@gmail.com

Insper, Rua Quatá, 300, Vila Olímpia, 04546-042, São Paulo/SP, Brasil

* Submetido: 06-09-2016

* Aceite: 31-01-2017 